\title{
Editorials
}

\section{General practice and the Sustainability and Transformation imperatives}

Sustainability and Transformation Plans (STPs) have now been submitted for all 44 areas across England, swiftly followed by corresponding plans from clinical commissioning groups (CCGs) for how they intend to strengthen and transform health services across their communities. CCGs were required to outline how the investment described in the General Practice Forward View (GPFV) will be utilised to support general practice, to reverse some of the damage done by years of underinvestment, and create a position from which primary care can begin to strengthen. ${ }^{1}$ Stronger general practice is an imperative for the sustainability of STPs if the NHS is to function in a form recognisable from its founding principles.

\section{GENERAL PRACTICE HAS THE EXPERTISE}

When people feel unwell, they look to the trusted places within their NHS. It is GP surgeries that have the expertise to provide comprehensive, generalist first-contact care, but when they are unable to meet demand people predictably seek help in accident and emergency (A\&E); a place ill designed for their problems. On presenting to $A \& E$, the likelihood of someone having a preventable admission is directly related to the number of chronic health conditions they suffer with and effective primary care has been shown to reduce such admissions, ${ }^{2-4}$ with continuity of care being one important associated factor. With the average cost of 1 night's stay in hospital being estimated in 2015 to be three times the average annual cost of GP care for a whole year ( $€ 400$ versus $€ 136$ ) this clearly needs addressing. 5,6

\section{IMPROVE SERVICES TO DEPRIVED AREAS}

The problem is particularly acute in our most deprived areas. It is in these 'deep end' practices where significantly more people present with multiple health conditions, and where multimorbidity develops at a much younger age. ${ }^{7.8}$ Decisions about funding and investment should address the fact that current funding formulae inadequately recognise this greater need, but addressing this inequity to provide greater access is only part of the story.?

\section{MANAGE EXPECTATIONS}

Across the board, the gatekeeping role of

\section{"It is GP surgeries that have the expertise to provide comprehensive, generalist first-contact care, but when they are unable to meet demand people predictably seek help in accident and emergency (A\&E); a place ill designed for their problems.}

general practice is critical. To illustrate this, recent work carried out by a public health doctor in NHS Greater Glasgow and Clyde to understand why the Health Board was in persistent financial over-spend land how its high activity levels might squeeze into a smaller bed complement) also revealed rising use of $A \& E$, relative overuse of elective care by the affluent, and steep rises in emergency admissions as key problems. When health economies characterised by large areas of social deprivation under-provide to the poor and over-provide to the affluent, the funding formula responds by penalising funding for the socially deprived still further. ${ }^{10}$

We therefore propose that a 'sustainability imperative' is that appropriate transformation funds are channelled into addressing inequities in provision of general practice and ensuring that a coordinated, fully-functioning general practice service is available to all. Unfortunately the Royal College of General Practitioners' interim review of STPs shows most fail to recognise this, with great variability in GP involvement and some even advocating a reduction in GP workforce. ${ }^{11}$

\section{EFFECTIVE CLINICAL SUPPORT}

Even with such investment, managing significantly more care in the community will be a huge challenge. The extra GPs described in the GPFV will help if they can be found, but the shift of care will not be achieved safely without an even greater number of additional clinical support roles, led by GPs, providing high quality generalist care. General practice will continue to increasingly depend on these support roles to be effective. Yet this is where the evidence becomes thinner. Each month new (and old) roles are proposed as part of the solution: pharmacists, care navigators, physician associates, paramedics, with little evidence to show how they might successfully strengthen teams without losing the core features of general practice that help sustain the NHS. ${ }^{12}$

\section{INVEST EARLY IN THE TRANSFORMATION CYCLE}

For general practice to embark on this transformation it needs confidence that these support roles will emerge in sufficient numbers with the right competencies. Modelling such a transformation in one STP footprint suggests a greater increase in numbers that those described in the GPFV is required. ${ }^{13}$ Although some of the necessary training is already present in some areas, the numbers are not currently sufficient and the more novel roles are still in their infancy in terms of integrating into primary care.

The 'transformation imperative' is therefore that sufficient STP funds are invested to pump-prime the structures to rapidly train the clinical support required.

\section{"When health economies characterised by large areas of social deprivation under-provide to the poor and over-provide to the affluent, the funding formula responds by penalising funding for the socially deprived still further.}




\section{“... without a strong, resilient, and highly functioning primary care service, the credibility, and indeed safety, of the STP programme is questionable.}

Further research is also urgently required in how general practice can best transform without losing its core essence. ${ }^{12}$

The GPFV provides an important statement to GPs of their value, and describes how the previous damaging underinvestment in general practice can be corrected, but urgently needs to become a reality at the front line, where general practice is stretched to its limit. ${ }^{14}$ The STPs take the NHS into unknown territory, and with significant risk. As described in the recent Kings Fund report, without a strong, resilient, and highly functioning primary care service, the credibility, and indeed safety, of the STP programme is questionable. ${ }^{15}$ Early investment to strengthen primary care for our most deprived populations and develop the necessary clinical support roles for primary care, along with better evidence on how new teams will emerge are imperatives for the success of the whole venture.

\section{ADDRESS FOR CORRESPONDENCE}

University of Sheffield, Academic Unit of Primary

Care, Samuel Fox House, Northern General

Hospital, Sheffield S5 7AU, UK

\section{E-mail: ben.jacksondsheffield.ac.uk}

\section{Ben Jackson,}

Senior Clinical Teacher, Academic Unit of Primary Medical Care, University of Sheffield, Sheffield.

\section{Helene Irvine,}

Consultant in Public Health, NHS Glasgow and the Clyde, Glasgow.

\section{Elizabeth Walton,}

NIHR Clinical Fellow, Academic Unit of Primary Medical Care, University of Sheffield, Sheffield.

\section{Provenance}

Freely submitted; externally peer reviewed.

DOI: https://doi.org/10.3399/bjgp17X690569

\section{Ben Jackson}

\section{REFERENCES}

. NHS England. General practice forward view. 2016. https://www.england.nhs.uk/wp-content/ uploads/2016/04/gpfv.pdf laccessed 5 Apr 2017).

2. Payne RA, Abel GA, Guthrie B, Mercer SW. The effect of physical multimorbidity, mental health conditions and socioeconomic deprivation on unplanned admissions to hospital: a retrospective cohort study. Can Med Assoc J 2013; 185(5): E221E228.

3. Busby J, Purdy S, Hollingworth W. Opportunities for primary care to reduce hospital admissions: a cross-sectional study of geographical variation. Br J Gen Pract 2017; DOI: https://doi.org/10.3399/ bjgp16X687949.

4. Barker I, Barker I, Steventon A, Deeny SR Association between continuity of care in general practice and hospital admissions for ambulatory care sensitive conditions: cross sectional study of routinely collected, person level data. BMJ 2017; 356: $j 84$.

5. Department of Health. NHS hospital stay. 2015 https://data.gov.uk/data-request/nhs-hospital-stay (accessed 5 Apr 2017).

6. Health \& Social Care Information Centre. NHS Payments to General Practice, England 2014/2015. http://content.digital.nhs.uk/catalogue/PUB18468/ nhspaymentsgp-14-15-rep.pdf laccessed $10 \mathrm{Apr}$ 2017).

7. Mercer SW, Watt GCM. The inverse care law: Clinical primary care encounters in deprived and affluent areas of Scotland. Ann Fam Med 2007; 5(6): 503-510.

8. Barnett K, Mercer SW, Norbury M, et al. Epidemiology of multimorbidity and implications for health care, research, and medical education: a cross-sectional study. Lancet 2012; 380: 37-43.

9. Levene LS, Baker R, Wilson A, et al. Population health needs as predictors of variations in NHS practice payments: a cross-sectional study of English general practices in 2013-2014 and 2014-2015. Br J Gen Pract 2016; DOI: https://doi. org/10.3399/bjgp16X688345.

10. IIrvine $\mathrm{H}$, Gomez J. Using routinely collected data to figure out where the NHS is going wrong. 2015 http://wnw.gla.ac.uk/media/media_443697_en.pdf laccessed 10 Apr 2017)

11. Royal College of General Practitioners. GP Forward View interim assessment. 2017. http://unw. rcgp.org.uk/-/media/Files/Policy/2017/RCGP_ GP-Forward-View-Interim-Assessment-2017. ashx?la=en. (accessed 5 Apr 2017).

12. Marshall M, Gray DP. General practice is making a leap in the dark. BMJ 2016; 355: i5698.

13. Health Education England. South Yorkshire \& Bassetlaw Primary Care Workforce group. Proposa to STP executive and LWAB for investment to build a multi-professional primary care workforce across South Yorkshire and Bassetlaw. 2016. https:// sybwg.files.wordpress.com/2016/11/proposal-forinvestment-in-pc-workforce-transformation-sybfinal.pdf (accessed 5 Apr 2017).

14. Walton $\mathrm{E}$, Markus $\mathrm{K}$, Torkington $\mathrm{M}$, et al. Re: General practice is making a leap in the dark [letter] http://wnw.bmj.com/content/355/bmj.i5698/rr-2 (accessed 5 Apr 2017).

15. Ham C, Alderwick H, Dunn P, Mckenna H Delivering sustainability and transformation plans From ambitious proposals to credible plans. 2017. https://uww.kingsfund.org.uk/publications/ delivering-sustainability-and-transformation-plans (accessed 5 Apr 2017). 